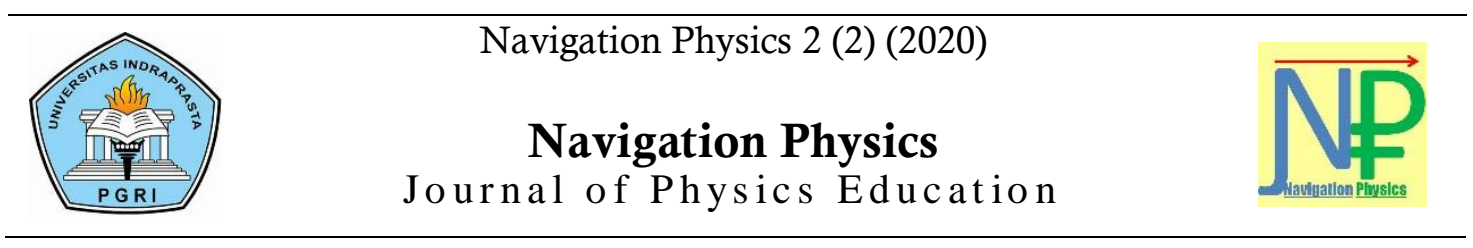

\title{
Studi Meta-Analisis Model Pembelajaran Inquiry Terbimbing dalam Pembelajaran Fisika
}

\author{
Nurhasanah ${ }^{1}$, Dasmo $^{1^{*}}$ \\ ${ }^{1}$ Universitas Indraprasta PGRI \\ *E-mail:amo0903unindra@gmail.com
}

\begin{tabular}{|c|c|}
\hline Info Artikel & Abstract \\
\hline $\begin{array}{l}\text { Sejarah Artikel: } \\
\text { Diterima November } 2020 \\
\text { Disetujui November } 2020 \\
\text { Dipublikasikan Desember } 2020 \\
\text { Keywords: } \\
\text { Meta-Analisis, Inquiry terbimbing, } \\
\text { Pembelajaran Fisika }\end{array}$ & $\begin{array}{l}\text { This study aims to analyze the influence of the guided inquiry learning } \\
\text { model in physics learning through the overall effect size, based on the } \\
\text { dependent variable and region. This research uses a descriptive method } \\
\text { with a meta-analysis approach to the results of scientific research } \\
\text { publications in national electronic journals. There are } 11 \text { national journals } \\
\text { that fit the research category. The results showed that overall learning using } \\
\text { the guided inquiry model could improve students' physics learning } \\
\text { outcomes with the effect size of } 0.487 \text { from the control group. Meanwhile, } \\
\text { based on the distribution of regions in Indonesia, an average effect size of } \\
0.527 \text { is obtained and based on the dependent variable an effect size is } \\
\text { obtained of } 0.425 \text {. These three results indicate a large effect size guided } \\
\text { inquiry learning model in physics learning. This shows that the guided } \\
\text { inquiry learning model can provide a more effective effect and is suitable } \\
\text { for use in learning physics. }\end{array}$ \\
\hline
\end{tabular}

How to Cite: Nurhasanah, N., \& Dasmo, D. (2020). Studi Meta-Analisis Model Pembelajaran Inquiry Terbimbing dalam Pembelajaran Fisika. Navigation Physics, 2 (2): 69-73.

\section{PENDAHULUAN}

Perolehan prestasi sains peserta didik berdasarkan hasil survei internasional yang dilakukan oleh Programmer For International student Assessment (PISA) pada tahun 2018 menunjukkan bahwa kemampuan sains peserta didik di Indonesia masih belum optimal. Indonesia berada pada peringkat 70 dari 78 negara yang disurvei. Aspek penilaian sains pada survei tersebut meliputi pengetahuan, kompetensi dan sikap peserta didik pada materi fisika dan biologi (OECD, 2020). Berdasarkan kondisi di atas, kualitas pendidikan di Indonesia dapat meningkat jika kualitas pembelajaran dapat dioptimalkan dengan model pembelajaran yang tepat. Hakim dan Lia (2020: 39) mengemukakan bahwa model pembelajaran pada hakikatnya adalah sebuah proses interaksi baik langsung maupun tidak langsung antara guru dan peserta didik. Dalam melakukan proses interaksi tersebut, tentunya guru harus menyesuaikan dengan gaya belajar dan kebutuhan belajar peserta didik agar tujuan pembelajaran dapat tercapai sesuai dengan harapan. Guru harus bisa menggunakan model pembelajaran yang tepat agar peserta didik memperoleh hasil belajar yang baik. Salah satu model yang dapat diterapkan yaitu model pembelajaran inquiry terbimbing. Model pembelajaran inquiry adalah model pembelajaran yang menekankan proses berpikir peserta didik secara kritis dan analitis untuk mencari dan menemukan sendiri jawaban dari suatu masalah yang diajukan (Kristanto dan Susilo, 2015:198). Berdasarkan hal tersebut, model pembelajaran ini sangat terkait dengan pengetahuan, kompetensi, dan sikap peserta didik pada sains sesuai dengan salah satu kriteria penilaian PISA. Dengan kata lain, model pembelajaran ini dapat dijadikan alternatif solusi dalam peningkatan kualitas pembelajaran sehingga pengetahuan, kompetensi, dan sikap peserta didik pada sains menjadi lebih baik sehingga dapat meningkatkan prestasi sains. 
Hidayat dkk (2019: 106) langkah-langkah pembelajaran inquiry antara lain: menyajikan masalah, membuat hipotesis, pengumpulan data, pengujian hipotesis/mengolah data dan penarikan kesimpulan. Sementara itu, model pembelajaran inquiry terbimbing adalah model pembelajaran dimana guru membimbing peserta didik melakukan kegiatan dengan memberi pertanyaan awal dan mengarahkan pada suatu diskusi (Widyawati dkk, 2019). Artinya rangkaian kegiatan yang melibatkan secara maksimal seluruh kemampuan peserta didik untuk mencari dan menyelidiki secara sistematik, kritik, logik dan analitik sehingga peserta didik dapat merumuskan suatu masalah dan menyelesaikannya dengan sendiri. Ibe (2013) mengemukakan bahwa model dengan pembelajaran inquiry terbimbing guru dapat memberikan kesempatan yang luas bagi peserta didik untuk belajar, berpikir kritik, dan berdiskusi dengan rekanrekannya. Seperti yang telah dijelaskan sebelumnya bahwa model pembelajaran ini dapat dijadikan alternatif solusi dalam peningkatan kualitas pembelajaran sehingga pengetahuan, kompetensi, dan sikap peserta didik pada sains menjadi lebih baik sehingga dapat meningkatkan prestasi sains dan peringkat PISA Indonesia.

Yeritia dkk (2017: 186) dari hasil penelitiannya menyimpulkan bahwa dengan model inquiry terbimbing dapat meningkatkan keterampilan proses sains. Sedangkan Retnosari dkk (2016: 1535) menghasilkan kesimpulan bahwa terdapat perbedaan hasil belajar antara peserta didik yang diajarkan menggunakan model inquiry terbimbing dengan peserta didik yang diajarkan menggunakan model pembelajaran konvensional. Berdasarkan 30 penelitian sejenis yang peneliti kumpulkan maka perlu dilakukan penggalian informasi sebanyak mungkin mengenai pengaruh model pembelajaran inquiry terbimbing dalam pembelajaran fisika dengan menggunakan teknik meta-analisis. Meta-analisis adalah penelitian yang dilakukan dengan cara merangkum data penelitian, mereview dan menganalisis data penelitian dari beberapa hasil penelitian yang sudah ada sebelumnya. Pengumpulan data penelitian dilakukan dengan cara menelusuri artikel-artikel yang terdapat pada jurnal, hasil skripsi, tesis atau disertasi di repository (Anadiroh, 2019:19).

Setiap tahun terdapat hasil penelitian di bidang pendidikan yang mengambil tema model pembelajaran inquiry terbimbing dipublikasikan sebagai media berupa jurnal. Penelitian tersebut berupa eksperimen, deskriptif, dan sebagainya. Data mengenai hasil penelitian pembelajaran inkuiri terbimbing cukup banyak, akan tetapi hanya sebatas menguji efektivitasnya. Penelitian lanjutan mengenai data tersebut belum banyak dilakukan.Untuk mengetahui pengaruh yang dihasilkan, maka perlu dilakukan perhitungan besar pengaruh (effect size) sehingga dapat dipetakan dan dianalisis pengaruh yang terlibat dalam pembelajaran inquiry terbimbing. Effect size menunjukkan besarnya pengaruh dari suatu perlakuan atau kekuatan hubungan antara dua variabel. Dengan menentukan effect size dari setiap penelitian, maka secara keseluruhan dapat ditemukan dan ditentukan bagaimana besar pengaruh suatu perlakuan. Penelitian ini menggunakan sampel berupa penelitian terdahulu dengan topik sejenis untuk memperoleh informasi dan dapat dianalisis besar pengaruhnya. Berdasarkan pemaparan tersebut, penelitian ini membahas tentang "Studi Meta-Analisis Model Inquiry Terbimbing dalam Pembelajaran Fisika".

\section{METODE PENELITIAN}

Penelitian ini menggunakan metode penelitian deskriptif dengan pendekatan meta-analisis, yaitu telaah sistematik yang disertai teknik statistik untuk menghitung kesimpulan beberapa penelitian. Penelitian ini menggunakan hasil publikasi penelitian ilmiah pada jurnal elektronik pada tingkat nasional yang berkaitan dengan pengaruh model pembelajaran inquiry terbimbing dalam pembelajaran fisika. Jurnal yang dianalisis sebagai sampel dalam penelitian ini berjumlah 11 jurnal nasional dari 30 jurnal baik yang terakreditasi SINTA maupun yang belum terakreditasi. 11 jurnal tersebut merupakan jurnal yang sudah terverifikasi berdasarkan kriteria-kriteria yang dijadikan fokus penelitian. Instrumen yang digunakan dalam penelitian ini adalah lembar pemberian kode (coding data). Unit dasar studi meta-analisis adalah effect size, maka untuk menjawab rumusan masalah penelitian digunakan perhitungan dengan teknik analisis besaran (effect size). Effect size adalah indikator yang mengukur besarnya efek dari suatu perlakuan. Penelitian yang melibatkan dua kelompok yaitu kelompok eksperimen dan kelompok kontrol, menggunakan analisis komparasi dengan teknik analisis uji-t. Formula effect size yang digunakan adalah sebagai berikut:.

$$
r=\sqrt{\frac{t_{0}{ }^{2}}{\left(t_{0}{ }^{2}+d b\right)}}
$$

dimana:

$$
\begin{aligned}
& \mathrm{r}=\text { ukuran effect size } \\
& \mathrm{t}=\text { hasil } \mathrm{t} \text { statistik } \\
& \mathrm{d} b=\text { degree (Angeline \& Meiden (2019: } 41 \text { ) }
\end{aligned}
$$


Sedangkan menurut Kadir (2017: 165) untuk penelitian eksperimen melibatkan lebih dari dua kelompok, menggunakan analisis komparasi dengan teknik analisis Anova-1 jalan, dengan formula sebagai berikut.

$$
\boldsymbol{n}^{2}=\frac{J \boldsymbol{K}_{\text {antara }}}{J \boldsymbol{K}_{\text {total }}}
$$

Begitupun untuk penelitian eksperimen yang melibatkan lebih dari dua kelompok dan interaksinya, menggunakan analisis komparasi dengan teknik analisis Anova-2 Jalan, maka formula yang digunakan sebagai berikut.

$$
\begin{aligned}
n_{A}{ }^{2} & =\frac{J K(A)}{J K(A)+J K(D)} \\
n_{B}{ }^{2} & =\frac{J K(B)}{J K(B)+J K(D)} \\
n_{A B}{ }^{2} & =\frac{J K(A B)}{J K(A B)+J K(D)}
\end{aligned}
$$

Menurut Surata (2020: 24) penelitian eksperimen dengan asumsi kelompok heterogen dua kelompok formula yang digunakan yaitu:

$$
\Delta=\frac{\bar{X}_{E}-\bar{X}_{K}}{S_{K}}
$$

Kriteria yang digunakan untuk membentuk intepretasi hasil effect size menggunakan acuan dari Anadiroh (2019: 35) yaitu:
$0.01<$ Effect Size $\leq 0,09$
$0,09<$ Effect Size $<0,25$
$=$ Kecil
Effect Size $>0.25$

$$
=\text { Sedang }
$$$$
=\text { Besar }
$$

\section{HASIL DAN PEMBAHASAN}

Hasil

Data besar pengaruh (effet size) artikel publikasi ilmiah pembelajaran inquiry terbimbing berdasarkan kategori terdiri dari tiga kriteria yaitu efek kecil $(0.01<$ Effect Size $\leq 0,09)$, efek sedang $(0,09<$ Effect Size $\leq$ 0.25) dan efek besar (Effect Size $>0,25$ ). Hasil studi-meta analisis dapat dilihat pada Tabel 1 berikut.

Tabel 1

Hasil Effect Size Model Pembelajaran Inquiry Terbimbing dalam Pembelajaran Fisika

\begin{tabular}{cccccc}
\hline No & $\begin{array}{c}\text { Kode } \\
\text { Artikel }\end{array}$ & Wilayah & Variabel Terikat & Effect Size & Kategori \\
\hline 1 & $3 \mathrm{~A}$ & Sumatera & Keterampilan Proses Sains & 0.931 & Besar \\
2 & $4 \mathrm{~A}$ & Nusa Tenggara & Keterampilan Proses Sains & 0.137 & Sedang \\
3 & $6 \mathrm{~A}$ & Sulawesi & Pemahaman Konsep & 0.703 & Besar \\
4 & $9 \mathrm{~A}$ & Sulawesi & Hasil Belajar & 0.026 & Kecil \\
5 & $11 \mathrm{~A}$ & Nusa Tenggara & Hasil Belajar & 0.228 & Sedang \\
6 & $13 \mathrm{~A}$ & Jawa & Kemampuan Berpikir Kritis & 0.098 & Kecil \\
7 & $17 \mathrm{~A}$ & Nusa Tenggara & Hasil Belajar & 0.908 & Besar \\
8 & $33 \mathrm{~A}$ & Sumatera & Keterampilan Proses Sains & 0.936 & Besar \\
9 & $35 \mathrm{~A}$ & Bali & Pemahaman Konsep & 0.453 & Besar \\
10 & $40 \mathrm{~A}$ & Sumatera & Hasil Belajar & 0.863 & Besar \\
11 & $49 \mathrm{~A}$ & Sulawesi & Keterampilan Proses & 0.070 & Kecil \\
\multicolumn{7}{r}{} & Rerata effect size secara keseluruhan & $\mathbf{0 , 4 8 7}$ & Efek Besar \\
& \multicolumn{2}{c}{ SD } & & \multicolumn{2}{c}{$\mathbf{0 6 8}$} \\
\hline
\end{tabular}

Berdasarkan tabel 1, penelitian ini menjawab 3 kategori analisis yang digunakan untuk meganalisis effect size model pembelajaran inquiry terbimbing dalam pembelajaran fisika. Pertama, secara keseluruhan hasil effect size menunjukkan nilai rata-rata sebesar 0,487 dengan simpangan baku 0,268 dengan kategori efek besar. Hasil analisis mengungkapkan bahwa secara keseluruhan rata-rata effect size model pembelajaran inquiry terbimbing yang dikaitkan dengan penelitian-penelitian yang bersifat eksperimental dari 11 artikel yang dianalisis tersebut secara keseluruhan memiliki pengaruh yang besar 
dalam pembelajaran fisika peserta didik. Kedua, effect size berdasarkan wilayah menunjukkan nilai rata-rata sebesar 0,527 dengan simpangan baku 0,452 dengan kategori efek besar. Wilayah yang dimaksud adalah tempat penelitian pada artikel yang berada pada wilayah pulau Jawa, pulau Sumatera, pulau Sulawesi, pulau Bali, dan pulau Nusa Tenggara. Ketiga, effect size berdasarkan variabel terikat menaunjukkan nilai rata-rata sebesar 0,425 dengan simpangan baku 0,416 yang menunjukkan efek besar. Variabel terikat yang dimaksud adalah variabel yang dipengaruhi oleh variabel bebas (penerapan model inquiry terbimbing) dalam pembelajaran fisika yang terdiri dari hasil belajar, keterampilan proses sains, kemampuan berpikir kritis, dan pemahaman konsep fisika.

\section{Pembahasan}

Inkuiri terbimbing merupakan suatu cara yang efektif untuk membuat variasi suasana pola pembelajaran sekolah meningkat (Candra dkk, 2019: 32) . Model pembelajaran inquiry terbimbing dapat memberikan kesempatan berpikir bagi peserta didik dan memberikan kesempatan untuk mengembangkan metode ilmiah dan sikap ilmiah yang dimiliki siswa. Model inquiry terbimbing adalah alternatif yang dapat digunakan dalam pembelajaran fisika untuk meningkatkan hasil belajar peserta didik. Secara keseluruhan model pembelajaran ini memiliki effect size yang besar dalam pembelajaran fisika. Hal ini menandakan bahwa model pembelajaran ini cocok diterapkan dalam pembelajaran fisika meskipun berbeda wilayah dan berbeda variabel terikatnya. Hal ini sesuai dengan hasil penelitian yang membuktikan bahwa penggunaan model inquiry terbimbing pada pembelajaran fisika efektif digunakan dengan latar belakang letak geografis yang berbeda. Pulau Bali memiliki effect size yang paling besar diikuti pula Sumatera, Nusa Tenggara, Sulawesi, dan Jawa. Khusus di pulau Jawa, model pembelajaran ini justru memiliki effect size yang kecil.

Berdasarkan kelompok variabel terikat yaitu hasil belajar, keterampilan proses sains, kemampuan berpikir kritis dan pemahaman konsep, perolehan besar rata-rata model pembelajaran inquiry terbimbing mengahsilkan kategori effect size besar. Variabel terikat pemahaman konsep memiliki effect size paling besar diikuti oleh keterampilan proses sains, hasil belajar, dan kemampuan berpikir kritik. Hal ini disebabkan karena kontribusi langkah pembelajaran inquiry terbimbing yang cukup mudah diimplementasikan saat proses pembelajaran terutama pada fase ketiga yaitu memandu investigasi mandiri maupun kelompok peserta didik aktif dalam menemukan solusi permasalahan sehingga peserta didik cenderung lebih mudah memahami konsep-konsep yang dipelajari karena peserta didik menemukan sendiri konsep-konsep tersebut melalui pencarian solusi dalam memecahkan masalah sehingga peserta didik lebih mudah memahami dan mengingatnya.

Selanjutnya, keterampilan proses sains merupakan kemampuan mental dan fisik yang diperlukan untuk dapat mempelajari ilmu pengetahuan dan teknologi secara lebih efektif. Keterampilan proses sains dapat dikembangkan melalui pengalaman dan digunakan dalam bentuk operasi mental dan tindakan fisik. Keterampilan proses sains penting untuk dilatihkan kepada peserta didik dalam rangka memfasilitasi peserta didik untuk dapat menemukan atau mengembangkan pengetahuan yang mereka miliki. Keterampilan proses sains juga dapat memberikan kesempatan kepada peserta didik untuk belajar melalui pengalaman dalam rangka menghasilkan dan menggunakan informasi ilmiah, melakukan penyelidikan ilmiah, dan menyelesaikan masalah. Dengan keterampilan proses sains yang dimiliki, peserta didik dapat memecahkan berbagai permasalahan, berpikir kritis, membuat keputusan, menemukan jawaban, dan memuaskan rasa ingin tahunya (Hariyadi dkk., 2016: 1567). Atas dasar itu, sangat relevan jika model pembelajaran inquiry terbimbing yang juga memiliki kesamaan konsep dengan keterampilan proses sains memiliki pengaruh yang besar. Peserta didik membutuhkan model ini untuk menuntun mereka dalam menyelesaikan permasalahan-permasalahan yang disajikan dalam pembelajaran.

Model pembelajaran inquiry terbimbing memiliki effect size yang besar dalam meningkatkan hasil belajar peserta didik. Dalam penerapannya model inquiry terbimbing tidak menerapkan sistem kompetensi melainkan kerja sama agar seluruh anggota mencapai hasil yang baik. Melalui proses tersebut peserta didik dapat saling membantu untuk meningkatkan hasil belajar satu sama lain. Selain itu model inkuiri terbimbing dapat dilakukan melalui praktikum yang dapat meningkatkan kreatifitas belajar peserta didik sehingga akan berpengaruh pada hasil belajarnya. Utami et al., (2019: 50) mengungkapkan bahwa semakin berkembang penuh keterampilan peserta didik, maka semakin sering mereka belajar. Kemudian, semakin sering mereka balajar tentang satu topik, semakin baik mereka mampu berpikir kritis tentang topik tersebut. Berdasarkan hasil penelitian tersebut maka model pembelajaran inquiry terbimbing dapat dijadikan sebagai salah satu alternatif solusi untuk meningkatkan kualitas pembelajaran dan prestasi sains sehingga peringkat PISA Indonesia dapat ter-upgrade.

\section{PENUTUP}


Secara keseluruhan pembelajaran dengan menggunakan model inquiry terbimbing dalam pembelajaran fisika memiliki effect size sebesar 0,487 dengan kategori efek besar. Hal tersebut menunjukkan bahwa pembelajaran dengan model inquiry terbimbing dapat memberikan pengaruh yang lebih efektif dan layak digunakan dalam pembelajaran fisika. Effect size berdasarkan wilayah menunjukkan nilai rata-rata sebesar 0,527 dengan simpangan baku 0,452 dengan kategori efek besar. Effect size berdasarkan variabel terikat menunjukkan nilai rata-rata sebesar 0,425 dengan simpangan baku 0,416 yang menunjukkan efek besar. Berdasarkan hasil tersebut, model pembelajaran inquiry terbimbing merupakan alternatif pembelajaran untuk meningkatkan pemahaman konsep, keterampilan proses sains, dan hasil belajar fisika.

\section{DAFTAR PUSTAKA}

Anadiroh, M. (2019). Studi Meta-Analisis Model Pembelajaran Problem Based Learning (Pbl).

Angeline, A., \& Meiden, C. (2019). Corporate Governance Dan Manajemen Laba Pada Beberapa Penelitian Skripsi Perguruan Tinggi, Studi Meta Analisis. Equity, 21 (1), 35.

Candra, D., Rosdianto, H., \& Murdani, E. (2019). Penerapan Model Pembelajaran Inkuiri Terbimbing untuk Meningkatkan Pemahaman Konsep Siswa Kelas VIII pada Materi Pesawat Sederhana. Variabel, 2 (1), 31.

Hakim, L., \& Lia, L. (2020). Pengaruh Video Pembelajaran Fisika Terhadap Pemahaman Konsep Siswa SMP. Jurnal Pendidikan Fisika dan Tekhnologi, 6(01), 45-52.

Hariyadi, D., Ibrohim, \& Rahayu, S. (2016). Pengaruh Model Pembelajaran Inkuiri Terbimbing Berbasis Lingkungan Terhadap Keterampilan Proses dan oenguasaan konsep IPA. Jurnal Pendidikan, 1(8), $1567-1574$.

Hidayat, R., Suardana, I. N., \& Sarini, P. (2019). Komparasi Model Pembelajaran Inkuiri Terbimbing Dan Model Pembelajaran Berbasis Masalah Ditinjau Dari Pemahaman Konsep Ipa Siswa. Jurnal Pendidikan Dan Pembelajaran Sains Indonesia (JPPSI), 2(2), 104.

Ibe, Helen, N. N. (2013). Effect of Guided-Inquiryand Expository Teaching Methods on Senior Secondary School Students' Performance in Biology in Imo State. Journal of Education Research and Behavioral Sciences (Online), 2 (4), 051-057.

Kadir, K. (2017). Meta-Analysis of the Effect of Learning Intervention Toward Mathematical Thinking on Research and Publication of Student. TARBIYA: Journal of Education in Muslim Society, 4(2), $162-175$.

Kristanto, Y. E., \& Susilo, H. (2015). Pengaruh Model Pembelajaran Inkuiri Terbimbing Terhadap Kemampuan Berpikir Kritis dan Hasi; Belajar IPA Siswa Kelas VII SMP. Jurnal Pendidikan dan Pembelajaran, 22 (2), 197-208.

OECD. (2020). PISA 2018 Results (Volume VI): Are Students Ready to Thrive in an Interconnected World? PISA, OECD Publishing, Paris, https://doi.org/10.1787/d5f68679-en.

Retnosari, N., Susilo, H., \& Suwono, H. (2016). Pengaruh Model Pembelajaran Inkuiri Terbimbing Berbantuan Multimedia Interaktif Terhadap Berpikir Kritis Siswa Kelas Xi Sma Negeri Di Bojonegoro. Jurnal Pendidikan - Teori, Penelitian, Dan Pengembangan, 1(8), 1529-1535.

Surata, I. K. (2020). Meta-Analisis Media Pembelajaran pada Pembelajaran Biologi. Journal of Education Technology, 4, 22-27.

Utami, P. (2019). Meta-Analisis Penggunaan Model Kooperatif dalam Pembelajaran Biologi. Skripsi: Universitas Isalam Negeri Syarif Hidayatullah Jakarta.

Yeritia, S., Wahyudi, W., \& Rahayu, S. (2017). Pengaruh Model Pembelajaran Inkuiri Terbimbing Terhadap Penguasaan Konsep Dan Kemampuan Berpikir Kritis Fisika Peserta Didik Kelas X SMAN 1 Kuripan Tahun Ajaran 2017/2018. Jurnal Pendidikan Fisika Dan Teknologi, 3(2), 181.

Widyawati, T. (2019). Efektivitas Penerapan Model Pembelajaran Inkuiri Konsep Ipa dan Keterampilan Proses Sains dalam Materi Interaksi Makhluk Hidup. Jurnal Pendidikan. 6 (2), 1-10 